\title{
Omanicotyle heterospina n. gen. et n. comb. (Monogenea: Microcotylidae) from the gills of Argyrops spinifer (Forsskål) (Teleostei: Sparidae) from the Sea of Oman
}

Gil Ha Yoon ${ }^{1 *}$, Sarah Al-Jufaili ${ }^{2}$, Mark A Freeman ${ }^{3}$, James E Bron ${ }^{4}$, Giuseppe Paladini ${ }^{4}$ and Andrew P Shinn ${ }^{4^{*}}$

\begin{abstract}
Background: The Sultanate of Oman's aquaculture industry is expanding with an on-going assessment of potential new fish species for culture. The king soldier bream, Argyrops spinifer (Forsskål) (Sparidae), is one such species that is under consideration. During a routine health assessment of specimens caught in the Sea of Oman throughout the period November 2009 to March 2011, a number of gill polyopisthocotylean monogeneans were recovered.

Methods: A subsequent study of the monogeneans using a range of morphology-based approaches indicated that these were Bivagina heterospina Mamaev et Parukhin, 1974. In the absence of pre-existing molecular data, an expanded description of this species is provided, including a differential diagnosis with other species and genera belonging to the subfamily Microcotylinae Monticelli, 1892 with the subsequent movement of this species to a new genus to accommodate it.

Results: The polyopisthocotyleans collected from the gills of $A$. spinifer appear to be unique within the family Microcotylidae Taschenberg, 1879 in that, morphologically, they possess a pair of large, muscular vaginae each armed with a full crown of 16-18 robust spines and a unique dorsal region of folded tegument, which permits their discrimination from species of Bivagina Yamaguti, 1963. Sequencing of the SSU rDNA (complete 1968 bp) and LSU rDNA (partial 949 bp) places the specimens collected during this study within the subfamily Microcotylinae, but the LSU rDNA sequence differs from Bivagina and also from other microcotylid genera. Morphological features of $B$. heterospina sensu Mamaev et Parukhin, 1974 and the specimens collected from the current study are consistent with one another and represent a single species. The vaginal armature of these worms is unique and differs from all other genera within the Microcotylinae, including Bivagina, and its movement to Omanicotyle n. gen. to accommodate this species is proposed.
\end{abstract}

Conclusions: A new genus, Omanicotyle n. gen., is erected to accommodate Omanicotyle [Bivagina] heterospina n. comb. which represents the first monogenean to be described from Omani marine waters. Given the pathogenic potential of microcotylids on captive held fish stocks, a full assessment of Omanicotyle heterospina n. gen. et n. comb. is now required before large-scale production commences.

\footnotetext{
*Correspondence: ghyoon@squ.edu.om; aps1@stir.ac.uk

1 Department of Marine Science \& Fisheries, College of Agricultural \& Marine

Sciences, Sultan Qaboos University, P.O. Box 34, Al-Khod 123, Oman

${ }^{4}$ Institute of Aquaculture, School of Natural Sciences, University of Stirling,

Stirling FK9 4LA, UK

Full list of author information is available at the end of the article
} 


\section{Background}

In addition to the $\sim 150,000$ tonnes of commercially important species of wild marine fish landed through Omani ports [1], the Omani aquaculture industry, which currently exceeds 500 tonnes p.a. and primarily concerns the production of Dicentrarchus labrax (L.) and Oreochromis niloticus niloticus (L.) [1], is exploring the potential of a number of native species suitable for aquaculture. Of the $990+$ fish species known from Omani waters [2], approximately 50 species are under consideration for use in aquaculture, which will include an assessment of various species of seabream, grouper and snapper. Although global aquaculture production is expected to rise to meet the shortfall in wild catches, there is a parallel requirement to identify potential threats to the health and welfare of wild fisheries and aquaculture stocks so that contingencies to mitigate against their establishment or to minimise their potential impacts can be taken. During a recent assessment of these new aquaculture species by the Ministry of Fisheries Wealth, a sample of king soldier bream, Argyrops spinifer (Forsskål), was found to be infected with a microcotylid polyopisthocotylean monogenean, whose morphology is consistent with Bivagina heterospina Mamaev et Parukhin, 1974, which was previously described from the same host from Mokura Bay, Kuria Muria Islands in the Arabian Sea [3]. The morphological features of $B$. heterospina, however, appear unique and differ from other species of the genus Bivagina Yamaguti, 1963 and an expanded description of the microcotylid is provided in the current study. A new genus to accommodate this species is proposed.

\section{Methods}

\section{Collection of host and parasite material}

Thirty specimens of Argyrops spinifer, with a standard length of $26-52 \mathrm{~cm}$, were collected by line angling in the Oman Sea off the coastal city of Muscat and landed at Muttrah $\left(23^{\circ} 37^{\prime} 08.65^{\prime \prime} \mathrm{N}\right.$; $\left.58^{\circ} 35^{\prime} 33.76 \mathrm{E}\right)$ throughout the period November 2009 to June 2010. After landing, the fish were placed on ice and then directly transferred to the Ministry of Fisheries Wealth where the gills were excised. A total of 18 adult monogeneans (mean intensity of infection $0.6 \pm 1.0$ parasites fish $^{-1}$; range $0-3$ ) parasitising the gills, were removed using mounted surgical needles. Fifteen of the specimens were transferred directly into $90 \%$ ethanol for subsequent evaluation by staining, scanning electron and confocal laser scanning microscopy. The remaining three specimens were fixed in 95\% ethanol for molecular studies.

\section{Morphological methods}

Whole mounts of specimens $(n=7)$ were stained with Mayer's paracarmine to highlight features of the internal anatomy. Specimens were measured using an eyepiece graticule and all measurements are given in micrometres as the range followed by the mean in parentheses, unless otherwise stated. The terminology of structures follows that of Williams [4]; lengths refer to measurements taken along the longitudinal axis of the worm.

Additional ethanol fixed specimens $(n=5)$ were prepared for scanning electron microscopy by rehydrating down through a graded ethanol series to water and then by transferring them into $0.2 \mathrm{M}$ sodium cacodylate buffer $\mathrm{pH} 8$ for $24 \mathrm{~h}$, post-fixed in $1 \%$ osmium tetroxide for 2 hours at room temperature and then dehydrated through a graded ethanol series. Specimens were then transferred to 50:50 100\% ethanol: hexamethyldisilazane followed by 2 changes of $100 \%$ hexamethyldisilazane (45 min each), air dried overnight, mounted on $12.5 \mathrm{~mm}$ aluminium stubs (Agar Scientific Ltd., Stansted, UK) and then sputter-coated with gold using an Edwards Sputter Coater S150B. Specimens were viewed under a Jeol JSM $6460 \mathrm{LV}$ SEM, at an accelerating voltage of $10 \mathrm{kV}$.

A further three alcohol fixed specimens were processed for confocal laser scanning microscopy, by rinsing them in distilled water for $24 \mathrm{~h}$ and then transferring them to either 1) $40 \mathrm{mM}$ chromotrope 2R (C2R) (Alfa Aesar, Heysham, UK) $+3 \mathrm{mM}$ phosphotungstic acid (Sigma-Aldrich ${ }^{\circ}$, Poole, UK) $+0.5 \%$ acetic acid (SigmaAldrich $^{\circ}$ ) for $4 \mathrm{~h}$ at room temperature [5] to stain the attachment clamps and copulatory spines; or 2) $5 \mu \mathrm{l}$ $\left(0.2 \mathrm{U} \mathrm{Hl}^{-1}\right.$ methanol) Alexa Fluor ${ }^{\ominus} 594$ phalloidin (Invitrogen Molecular Probes, Eugene, Oregon, USA) in $100 \mu$ distilled water in the dark, at room temperature for $5 \mathrm{~h}$ to stain the muscular components of the worm. After staining, the specimens were rinsed and mounted in distilled water and then examined on a Leica TCS SP2 AOBS laser scanning confocal microscope.

Illustrations were prepared from images captured using a Zeiss AxioCam MRc digital camera mounted on top of an Olympus BX51 compound microscope using a $\times 0.75$ interfacing lens and $\times 10$ to $\times 100$ oil immersion objectives and MRGrab 1.0.0.4 (Carl Zeiss Vision GmbH, 2001) software.

\section{Molecular methods}

Three individual monogeneans, previously fixed in $95 \%$ ethanol, were digested overnight at $56^{\circ} \mathrm{C}$ in DNA buffer containing $100 \mu \mathrm{g} \mathrm{ml}^{-1}$ proteinase $\mathrm{K}$. Total DNA was extracted using a GeneMATRIX kit (EURx Poland) following the tissue protocol and used for PCR reactions. The small subunit ribosomal DNA (SSU rDNA) was amplified using the primers $18 \mathrm{e}, 390 \mathrm{f}, 870 \mathrm{f} / \mathrm{r}$ and $18 \mathrm{gM}$ [6-9]. The D1-D2 domains of the large subunit ribosomal DNA (LSU rDNA) were amplified using the primers $\mathrm{C} 1$ and D2 [10]. PCR bands of the correct size were visualised and recovered from the PCR products using a 
GeneMATRIX PCR products extraction kit (EURx Poland). PCR reactions were performed in triplicate (three separate worms) according to the original descriptions and sequencing reactions were performed using BigDyeTM Terminator Cycle Sequencing chemistry utilising the same oligonucleotide primers used for the original PCRs. DNA sequencing was performed in both directions for all PCR products and contiguous sequences obtained manually using CLUSTAL_X [11] and BioEdit [12]. CLUSTAL_X was used for the initial sequence alignments and regions of ambiguous sequence alignments were manually edited using the BioEdit sequence alignment editor [12]. Alignment files of related microcotylids, consisting of 947 characters of LSU rDNA sequence data, were used in the phylogenetic analyses. Phylogenetic analyses were performed using the maximum likelihood methodology in PhyML [13] with the general time-reversible (GTR) substitution model selected and 1000 bootstrap repeats, and Bayesian inference (BI) analyses using MrBayes v. 3.0 [14]. Models of nucleotide substitution were evaluated for the data using MrModeltest v. 2.2 [15]. The most parameterrich evolutionary model based on the Akaike Information Criterion (AIC) was the GTR + I + G (GTR + proportion Invariant + Gamma) model of evolution. Posterior probability distributions were generated using the Markov Chain Monte Carlo (MCMC) method with four chains being run simultaneously for 1,000,000 generations. Burn in was set at 2500 and trees were sampled every 100 generations making a total of 7500 trees used to compile the majority rule consensus trees.

Taxa used in the phylogenetic analysis with respective GenBank accession numbers in parentheses: Atrispinum acarne Maillard et Noisy, 1979 (AF311702); Bivagina pagrosomi (Murray, 1931) Dillon et Hargis, 1965 (AJ243678); Cynoscionicola "branquialis" (AF382050); Diplostamenides sciaenae (Goto, 1894) Lebedev, Parukhin et Roitman, 1970 (FJ432589); Microcotyle arripis Sandars, 1945 (GU263830); Microcotyle erythrinii van Beneden et Hesse, 1863 (AM157221); Microcotyle sebastis Goto, 1894 (AF382051); Pagellicotyle mormyri (Lorenz, 1878) Mamaev, 1984 (AF311713); Polylabris sillaginae (Woolcock, 1936) Dillon, Hargis et Harrises, 1983 (GU289509); Sparicotyle chrysophryii (van Beneden et Hesse, 1863) Mamaev, 1984 (AF311719).

\section{Type material examined}

The following museum type specimens were examined: 1 paratype (CNHE 203) and 8 voucher specimens (CNHE 2822, 2824, 2827) of Pseudobivagina aniversaria (Bravo-Hollis, 1979) Mamaev, 1986 (syn. Neobivagina aniversaria Bravo-Hollis, 1979) from the Cortez sea chub Khyposus elegans (Peters) from the Colección Nacional de Helmintos, Instituto de Biologia, Universidad Nacional
Autónoma de México, Mexico City, Mexico; 3 voucher specimens of Bivagina pagrosomi (NHM 1980.6.2.6-7) from the gills of the silver seabream Pagrus (syn. Chrysophrys) auratus (Forster); 4 voucher specimens of Microcotyle [labelled as Bivagina] centrodonti Brown, 1929 (NHM 1989.4.28.33-52) from the gills of the black seabream Spondyliosoma cantharus (L.); and 1 voucher specimen of Bivagina sp. (NHM 1985.11.8.27) from the gills of the red stumpnose bream Chrysoblephus gibbiceps (Valenciennes) from the national parasite collection maintained by the Parasites and Vectors Section, The Natural History Museum, London, UK. In addition, photographs of Bivagina tai (Yamaguti, 1938) from the gills of red sea bream Pagrus major (Temminck et Schlegel) were kindly provided for assessment by Professor Kazuo Ogawa from the Meguro Parasitological Museum, Tokyo, Japan. Although valuable type material of $B$. heterospina were not available for loan, photographs of paratype (acc. no. 12296) from the gills of A. spinifer caught in Mokura Bay, Kuria Muria Islands in the Arabian Sea on the $26^{\text {th }}$ August 1969 were generously provided by Dr Pavel Gerasev from the Zoological Institute of The Russian Academy of Sciences (ZIRAS), St Petersburg, Russia.

\section{Results}

\section{Class Monogenea Carus, 1863}

Family Microcotylidae Taschenberg, 1879

Subfamily Microcotylinae Monticelli, 1892

Omanicotyle n. gen.

\section{Diagnosis}

Body lanceolate. Haptor symmetrical, with numerous clamps arranged in two equal rows. Clamps of microcotylid type of approximate equal size. No terminal anchors present. Paired muscular, unarmed, septate buccal organs. Oesophagus simple without diverticula. Intestinal crura not symmetrical, largely co-extensive with vitellaria extending into the haptoral peduncle. Testes numerous, post-ovarian. Genital atrium muscular, unarmed. Two large, paired, muscular, dorsal, vaginae, each armed with a crown of robust equal sized spines. Germarium U-shaped. Germinal part of germarium approximately ovoid. Large, fusiform, operculated eggs with two polar filaments, an extensive apical filament and a short posterior filament. Conspicuous Y-shaped vitelline duct. Vitellaria extending into the haptor.

Type species: Omanicotyle heterospina (Mamaev et Parukhin, 1974) n. comb.

Etymology: The generic name refers to the type locality, Oman.

Omanicotyle heterospina (Mamaev et Parukhin, 1974) n. comb.

Syn. Bivagina heterospina Mamaev et Parukhin, 1974. 


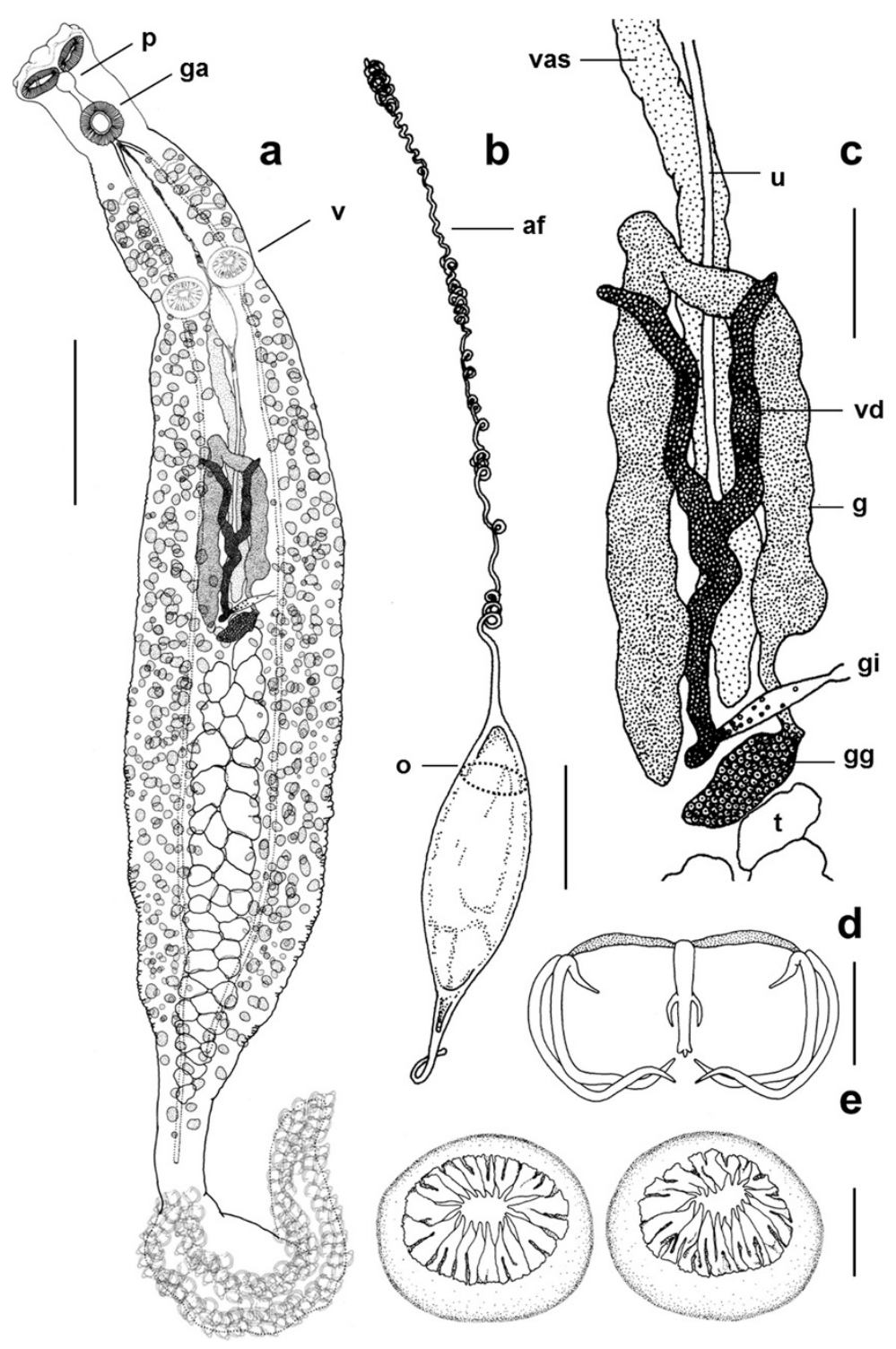

Figure 1 Omanicotyle heterospina $\mathbf{n}$. gen. et $\mathbf{n}$. comb. recovered from the gills of Argyrops spinifer (Forsskål). a, whole mount: ga, genital atrium; p, pharynx; v, vaginae. The vitellaria and pigment granules extend into the haptor but are not shown in full as they would obscure other body features. b, egg: af, anterior filament; $\mathrm{o}$, approximate position of the operculum. c, reproductive system: g, germarium; gg, germinal part of germarium; gi, genito-intestinal canal; $t$, testes; $u$, uterus; vas, vas deferens; vd, vitelline duct. d, clamp. e, paired, armed vaginae. Scale bars: $a=500 \mu m ; b, c=100 \mu m ; d=25 \mu m ; e=50 \mu m$.

Type host: King soldier bream, Argyrops spinifer (Forsskål) (Sparidae); wild (current study; [3]).

Other hosts: Soldierbream, Argyrops filamentosus (Valenciennes) [3].

Site on the host: Gills.

Type locality: Kuria Muria Islands, Arabian Sea (17 $28^{\prime}$ 06.14" N; 553ㅜ 55.18" E) [3].

Other localities: Sea of Oman landed at the port of

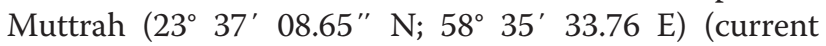
study).

Type material: Holotype (acc. no. 226/IO-1628) deposited in the Helminthology Laboratory of General
Biology and Soil Science of the USSR FESC. Paratypes (acc. no. 12296) are stored in the Laboratory of Parasitology of the Zoological Institute of the USSR.

Voucher material: Seven Mayer's paracarmine stained whole mounts prepared for the current study. Three voucher specimens (acc. no. NHMUK 2013.5.13.1-3) are deposited in the parasite collection of the Parasites and Vectors Section, The Natural History Museum (NHM), London. A further two specimens (USNPC acc. no. 106952.00) are deposited in the United States National Parasite Collection (USNPC), Beltsville, MD, USA; and two additional voucher specimens (acc. no. AHC 35684) 

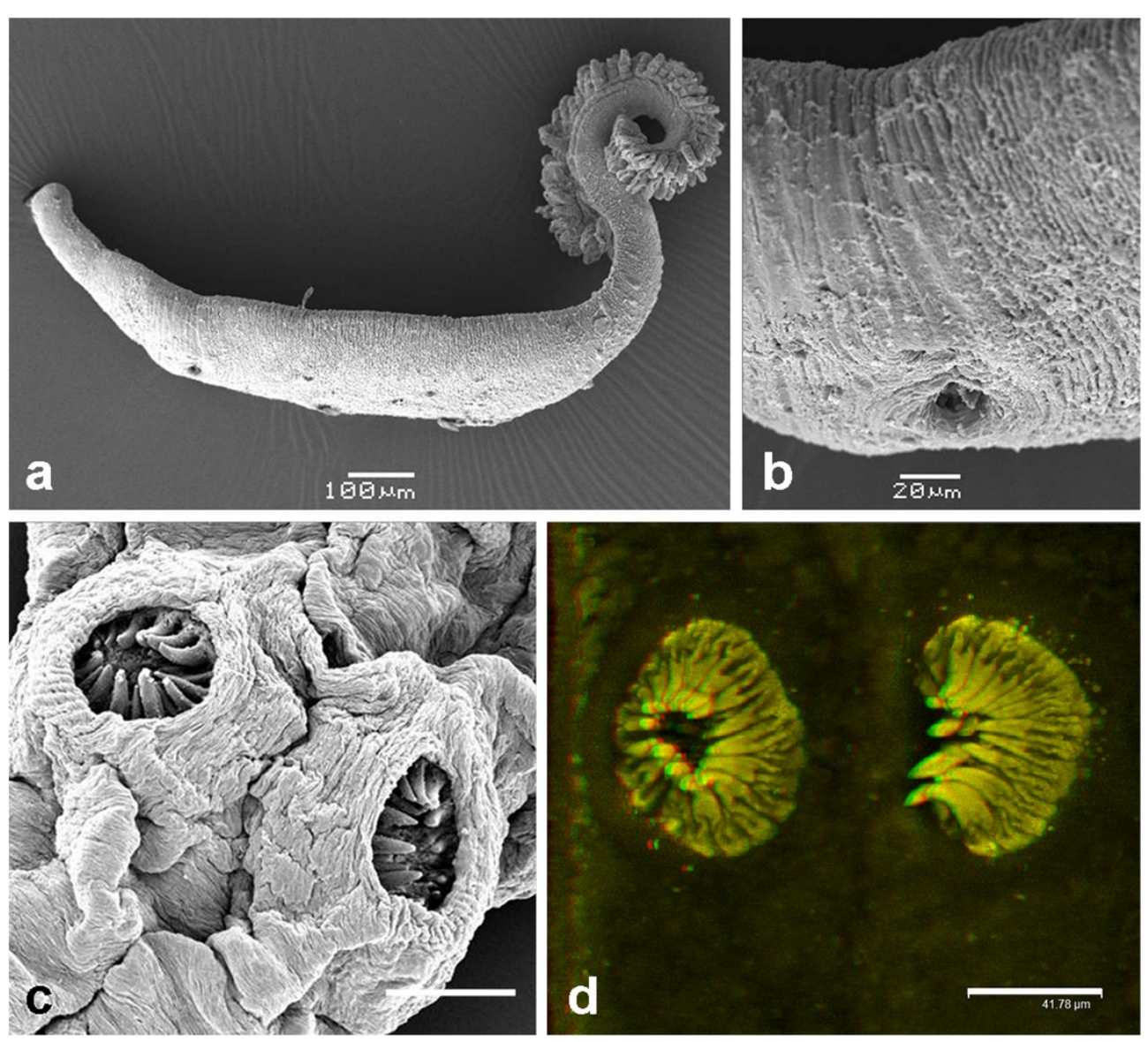

Figure 2 Omanicotyle heterospina n. gen. et $\mathbf{n}$. comb. from the gills of Argyrops spinifer (Forsskål). a, Scanning electron micrograph (SEM) of an entire specimen. $\mathbf{b}$, close up of the opening of one of the paired, dorsally positioned vaginae. $\mathbf{c}$, desiccated specimen prepared for SEM to reveal the crown of 16-18 spines within each vagina. $\mathbf{d}$, laser scanning confocal microscope image of the vaginal spines stained with a chromotrope $2 R$ based stain (see [4]). Scale bars: $a=100 \mu m ; b=20 \mu m ; c=50 \mu m ; d=41.8 \mu m$.

are deposited in the Australian Helminthological Collection (AHC) of The South Australian Museum (SAMA), North Terrace, Adelaide.

Molecular sequence data: A complete SSU rDNA sequence of $1968 \mathrm{bp}$ and a partial LSU rDNA sequence of 949 bp have been deposited in GenBank under the accession numbers JN602094 (SSU) and JN602095 (LSU), respectively.

General: To comply with the regulations set out in article 8.5 of the amended 2012 version of the International Code of Zoological Nomenclature (ICZN) [16], details of this species have been submitted to ZooBank with the Life Science Identifier (LSID) zoobank.org:pub: CDEC0135-BA59-4754-B213-5C748A02C818. In addition, a species profile including taxonomic traits, host details and additional metadata are provided on http:// www.monodb.org [17].

Description (based on 7 mature whole mounts): Body elongate with deep lateral constriction posterior to the genital atrium, a second lateral constriction in the vicinity of the vaginae and a narrow peduncle leading into the haptor (Figure 1). Total body length, including haptor, 4826 (2750-7375); 593 (275-775) in maximum width at the level of the germarium. Haptor symmetrical, delineated from the body, triangular, containing 45-50 pairs of clamps arranged in two equal rows (Figures 1a, 2a, and 3b). Lateral margins of the anterior part of the haptor well developed in its anterior part, the margins of which contain numerous $\mathrm{C} 2 \mathrm{R}$ positive droplets (Figure 3d). Clamps, of approximate similar shape but size slightly dissimilar; clamps develop in a posterior to anterior direction (Figure 3b-d). Anterior clamps 71 (68-75) wide, 36 (28-43) long; median clamps 76 (70-80) wide, 30 (28-38) long; posterior clamps 58 (48-65) wide, 34 (28-40) long. Haptoral hooks absent. Circular area of folded tegument on the dorsal surface, posterior to the vaginae approximately 70 long $\times 90$ wide (Figure 4a). This irregular folding of the tegument was present on all 7 specimens mounted for light microscopy; function unknown. Structure evident in specimens 

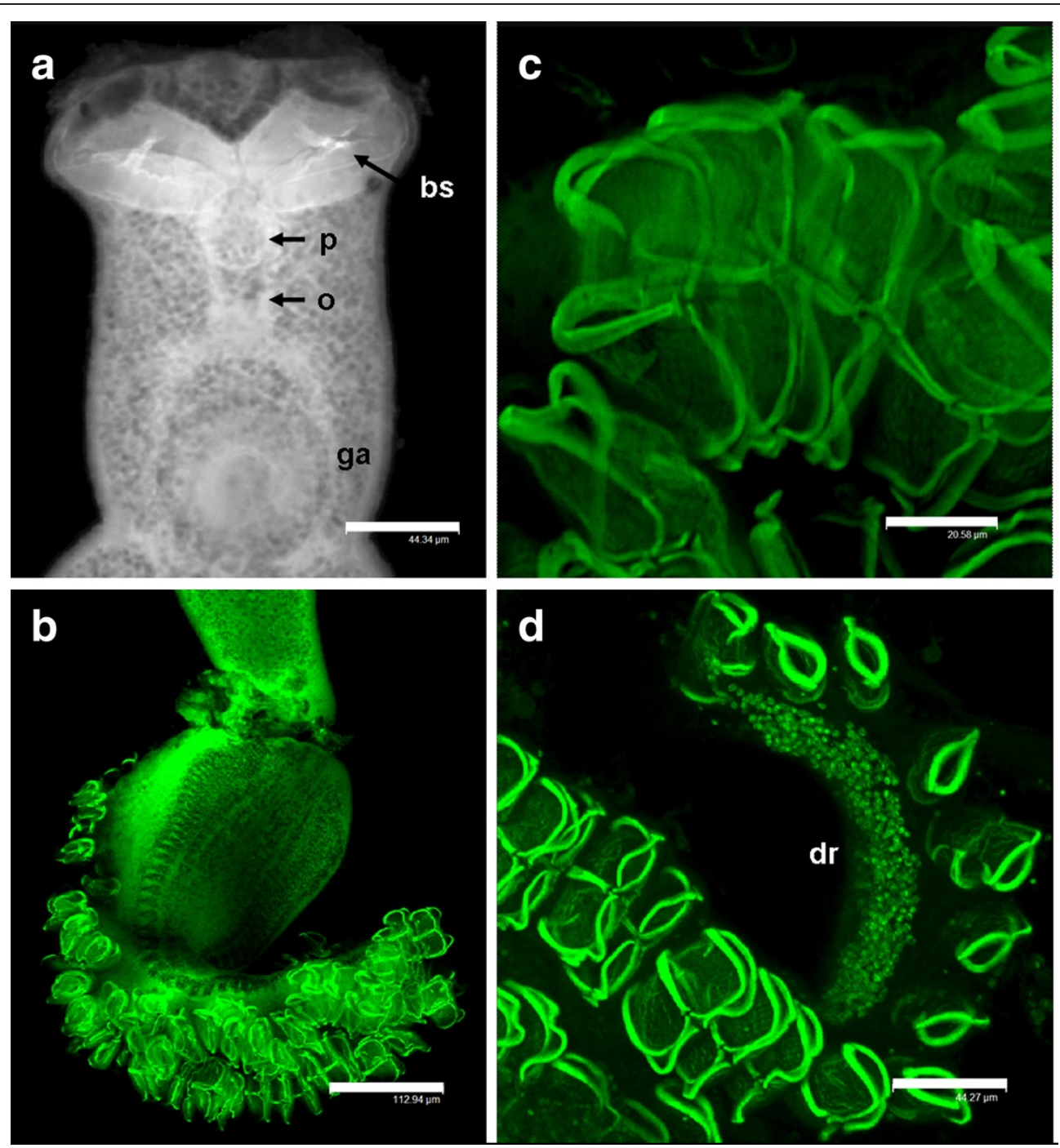

Figure 3 Laser scanning confocal micrographs of the anterior region and haptor of Omanicotyle heterospina $\mathrm{n}$. gen. et $\mathrm{n}$. comb. a, Muscular elements of the anterior region stained with Alexa Fluor 594 phalloidin. The septum of each buccal sucker (bs) is clearly evident. The lower edge of each sucker appears to be serrated or crenulated by contraction of the fine muscles in this region but are not spine bearing. The buccal cavity leads to a muscular circular pharynx (p), a short oesophagus (o) and an unarmed genital atrium (ga). b, oblique view of the symmetrical haptor which bears up to 50 pairs of clamps arranged in two equal rows. The vitellaria and pigment granules are visible as two parallel, dark, patterned bands running the length of the haptor. c, dual staining of the attachment clamps with phalloidin and the chromotrope 2R-based stain to reveal the main sclerotised component and the associated musculature. $\mathbf{d}$, anterior, forward projecting section of the haptor stained with $40 \mathrm{mM}$ chromotrope $2 \mathrm{R}(\mathrm{C} 2 \mathrm{R})+3 \mathrm{mM}$ phosphotungstic acid $+0.5 \%$ acetic acid for $4 \mathrm{~h}$ at room temperature. The photograph shows that clamps develop in a posterior to anterior direction and the lateral margins of this region of the haptor bear numerous C2R positive droplets (dr). Scale bars: $a=44.34 \mu \mathrm{m} ; b=112.94 \mu \mathrm{m} ; \mathrm{c}=20.58 \mu \mathrm{m} ; \mathrm{d}=44.27 \mu \mathrm{m}$.

prepared for SEM (see Figure 4a). Anterior region containing the buccal organs, pharynx and genital atrium, delineated from the main body by a sharp narrowing of the worm (Figures 1a, 2a, and 3a). Paired muscular buccal organs lacking discernible spines, 137 (113-158) long, 79 (45-100) wide, with septum 36 (25-60) long (Figure 3a); buccal cavity leading to a muscular circular pharynx 44 (40-48) long, 44 (35-53) wide. Oesophagus 124 (100-175) long. Intestinal caecae not equal in length, one terminates post-testicular, the other extends into the peduncle terminating just before the haptor. Short diverticula present in the anterior section posterior to the genital atrium, not evident throughout its entire length as obscured by vitellaria. Vitellaria irregular, not well defined, yellowish-brown in colouration, co-extensive with intestinal caecae, extending from the genital atrium to mid-way along the haptoral peduncle, each granule 40 (20-60) long, 21 (18-25) wide. Pigment granules distributed throughout the body, a light scattering anterior to the vaginae, below this they concentrate into two dark, 

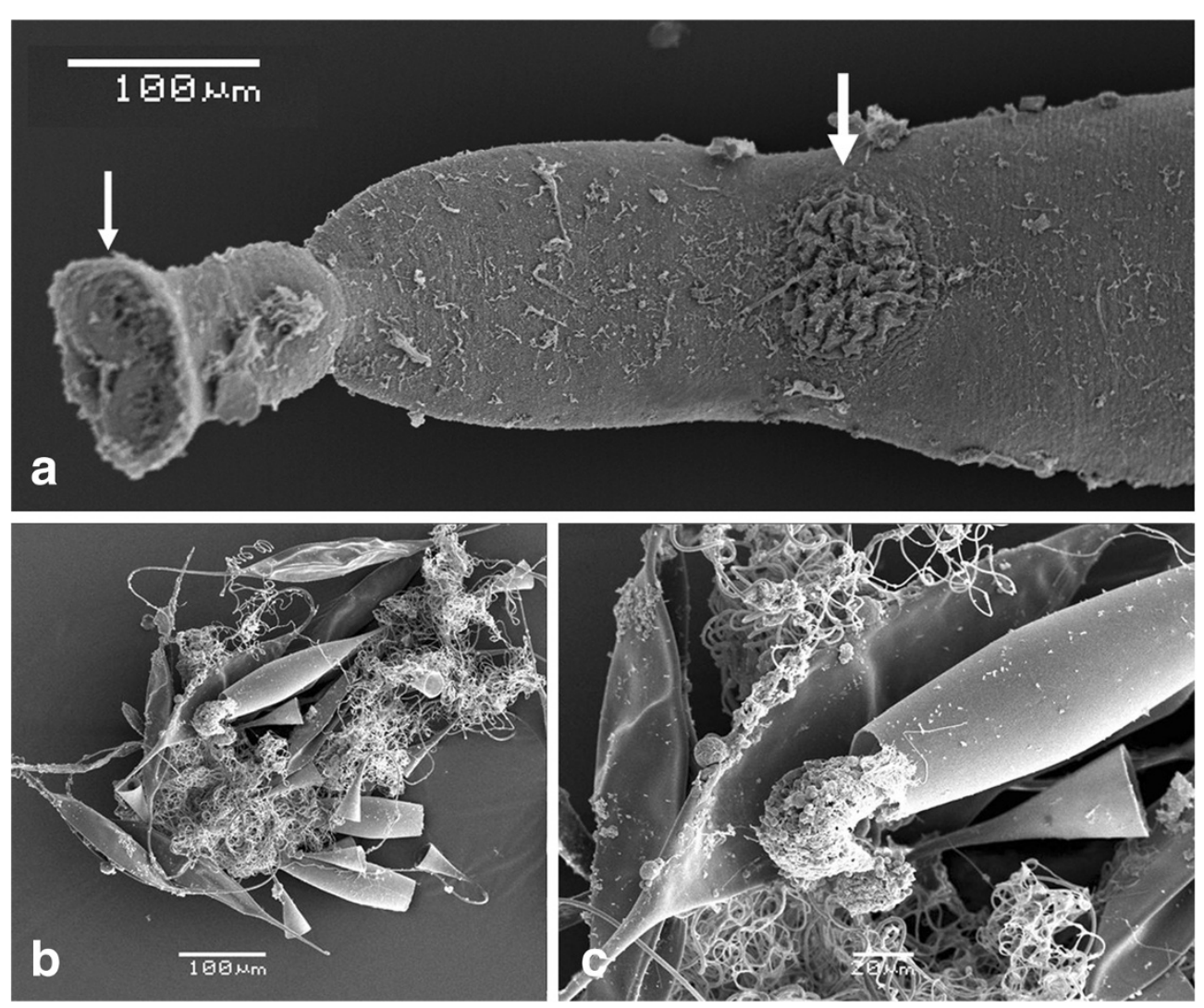

Figure 4 Scanning electron micrographs of Omanicotyle heterospina $\mathbf{n}$. gen. et $\mathbf{n}$. comb. $\mathbf{a}$, The anterior end of the worm, showing two septate buccal suckers (thin arrow), and its delineation from the main body. A circular area of irregular folded tegument on the dorsal surface is also evident (thick arrow), the precise function of which is unknown. b, the spindle shaped, operculated eggs, each bearing a short posterior filament and a long, tangled, apical filament which may exceed 10x the length of the egg proper. $\mathbf{c}$, a ciliated oncomiracidium emerging from an egg. Scale bars: $a, b=100 \mu m ; c=20 \mu m$

lateral bands that run the length of the body extending into and running the length of the haptor. Genital atrium unarmed, 77 (68-93) wide, 74 (63-88) long at its base; projects away from the body as a small cone. Two large, muscular vaginae 110 (90-130) wide, 120 (100-128) long, each armed with a crown of 16-18 robust spines, 24-28 long, which curve slightly towards the centre of the structure (Figures 1a,e and 2c,d). The muscles forming the wall of each vagina, 28 (25-30) thick. Worm narrows at mid-level of vaginae. Testes 42 (35-47) in number, situated in post-ovarian intercaecal field, not extending into the haptoral penduncle. U-shaped germarium median, pre-testicular, 754 (675-850) total length; 406 (337-550) length of the distal portion; 348 (275-475) length of the proximal part (excluding the germinal part of the germarium); germinal part of the germarium 96 (75-113) length $\times 55$ (43-63) width (observed in 6 specimens). Vitelline ducts Y-shaped, branches 191 (185-200) long, the posterior piece 242 (230-255) long, which leads into the genito-intestinal canal opening above the germinal part of the germarium. Fusiform, operculated eggs 230 long, 80 wide (present in 4 specimens). Very long, tangled, apical filament 1060 long, which tapers towards its extremity, the terminus of which is not thickened; posterior filament 110 long (Figures 1b, c and 4b,c).

\section{Remarks}

The original specimens of Omanicotyle [Bivagina] heterospina (Mamaev et Parukhin, 1974) n. comb. were collected from Kuria Muria Islands in the Arabian Sea, off the coast of Oman in July-August 1967 and in AugustSeptember 1969. This represents a separate water body, as recognised by the International Hydrographic Organisation, to the material collected from the Sea of Oman for the current study. There are, however, some small differences in the number of vaginal spines between the two collections. The material collected from the Arabian Sea have $20-25$ spines (25 spines on paratype ZIRAS acc. no. 12296) each measuring 48-54 in length, whilst the specimens collected for the current study have 16-18 spines, measuring 24-28 in length.

Each Omanicotyle specimen (18 individuals from 30 fish) was positioned on the outer hemibranch of the gill arch to which they were attached, orientated along the 
length of a single primary filament, the anterior end of the worm pointing towards the distal tip, with their clamps attached to the second lamellae; the posterior part of the haptor curling round the filament. The function of the numerous $\mathrm{C} 2 \mathrm{R}$ positive droplets along the lateral margins of the anterior haptor is unknown and can only be speculated upon. Given their high number and aggregation, it is unlikely that these represent the precursors for the synthesis of new clamps, i.e. they are not in close association with developing clamps. It could be suggested that these function as papillae increasing the surface area of this part of the haptor and make a contribution to the attachment of the worm. Unfortunately, this area was not visible on the specimens prepared for SEM; further specimens are therefore required to determine whether these structures are visible externally. According to Mamaev [18], parasites belonging to the subfamily Microcotylinae Monticelli, 1892 have either a single medio-lateral or rarely a dorso-laterally positioned vagina or occasionally two dorso-laterally situated vaginae. Given the large size of the vaginae, which occupy almost the entire width of the worm, it cannot be said that they are strictly dorso-lateral or medial.

\section{Differential diagnosis}

Omanicotyle n. gen. can be differentiated from the other 24 genera in the subfamily Microcotylinae on the basis of vaginal number (single or paired) and its relative armature, and also by armature of the genital atrium. The species belonging to the following genera all possess a single, unarmed vagina: Atriostella Unnithan, 1971; Caballeraxine Lebedev, 1972; Diplostamenides Unnithan, 1971; Gamacallum Unnithan, 1971; Jaliscia Mamaev et Egorova, 1977; Magniexcipula Bravo-Hollis, 1981; Paramicrocotyloides Rohde, 1978; Paranaella Kohn, BaptistaFarias et Cohen, 2000; Pauciconfibula Dillon et Hargis, 1965 (syn. Bradyhaptorus Unnithan, 1971); Polymicrocotyle Lamothe-Argumedo, 1967; Pseudoaspinatrium Mamaev, 1986; Sciaenacotyle Mamaev, 1989 (single opening with paired vaginal ducts); and, Solostamenides Unnithan, 1971. Whilst those belonging to Monomacracanthus Mamaev, 1976 and Sebasticotyle Mamaev et Egorova, 1977 possess a single, armed vagina. Species belonging to the genus Microcotyle van Beneden et Hesse, 1863 , also have a single, typically mid-dorsally positioned, vagina that is unarmed although the genus also includes species with an armed vagina (e.g. Microcotyle pamae Tripathi, 1954; see [19]). The remaining genera in the subfamily possess paired vaginae. Species belonging to the following genera have unarmed vaginae: Bivagina Yamaguti, 1963 (certain species within the genus); Diplasiocotyle Sandars, 1944; Lutianicola Lebedev, 1970; Neobivagina Dillon et Hargis, 1965 [based on Neobivagina canthari (van Beneden et Hesse, 1863) Dillon et Hargis, 1965 which
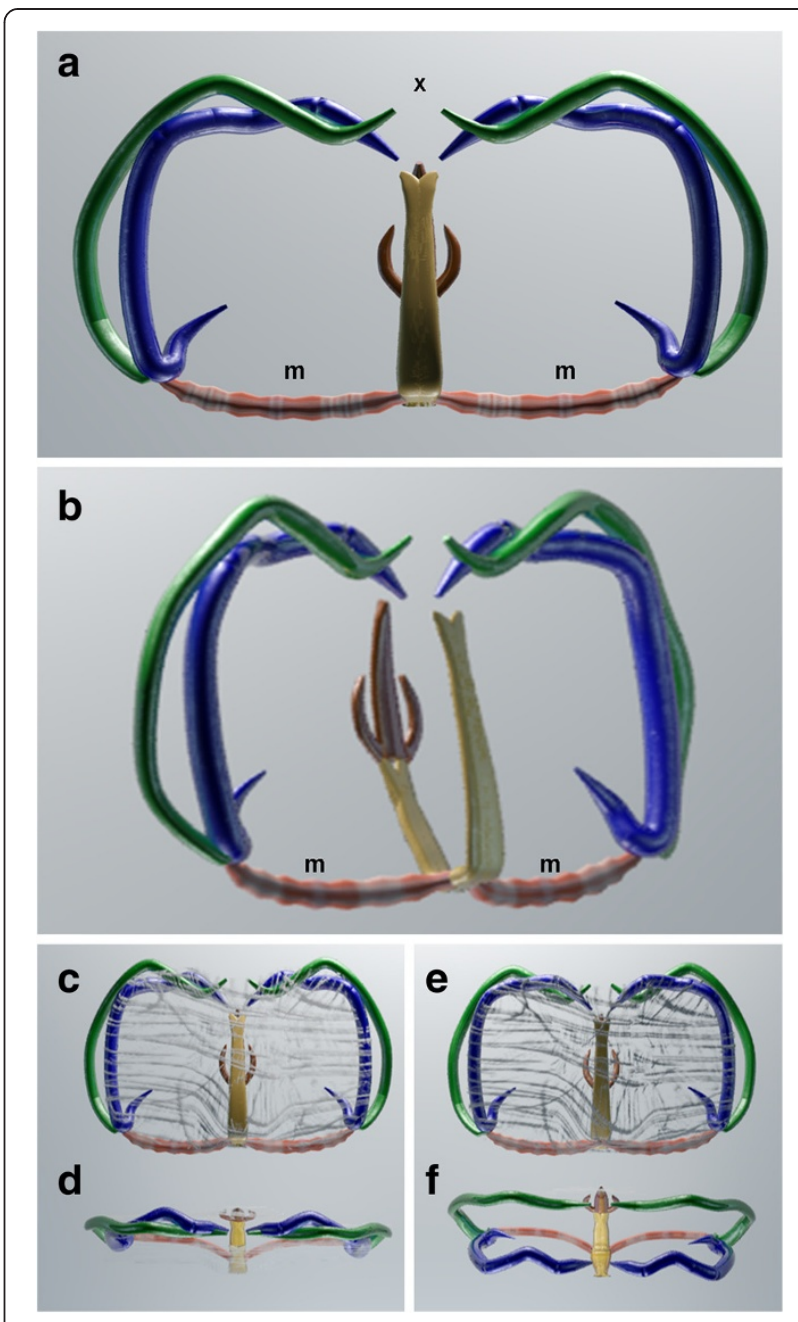

Figure 5 Graphics representing the main components of the attachment clamps of Omanicotyle heterospina $n$. gen. et $n$. comb. a, Median view. The clamp is in an upright position, the sclerites on the edge marked " $x$ " open and attach to the secondary lamellae of the host's gills. Large muscles ( $m$ ) linking the sclerites, whilst others (not shown) run throughout the tegument that encases the entire clamp apparatus. b, medio-lateral view. c, median view of a clamp in the closed or "clamped" position. Supporting muscles that run through the tegument are shown. $\mathbf{d}$, medio-ventral view of a closed clamp; e, median view of a clamp in the open position. $\mathbf{f}$, medio-ventral view of an open clamp.

was nominated by Mamaev [18] as the type species, following the reallocation of the other species in the genus to other genera]; Pseudobivagina Mamaev, 1986; and Pseudoneobivagina Mamaev, 1986. The remaining genera, which also include Omanicotyle n. gen., all have armed vaginae, i.e. Bivagina Yamaguti, 1963 (certain species within the genus); Kahawaia Lebedev, 1969; and Neobivaginopsis Villalba, 1987. Omanicotyle n. gen. can be readily discriminated from the other genera. The vaginae in Bivagina are typically small but heavily muscularised structures armed with a crescent of short spines; the 
vaginal ducts connecting the two vaginae are typically clearly visible. Kahawaia possesses two cuticularised, pyriform pads armed with spines, interpreted as vaginae. The vaginae of Neobivaginopsis are large, muscular, contractile structures the openings of which have lightly sclerotised borders. The vaginae of Omanicotyle n. gen. by comparison, are large, muscular structures with a full corona of spines, which near abut against each other and occupy almost the entire width of the worm and as such obscure the vaginal ducts (which could not be seen in the specimens examined for the current study).

Omanicotyle $\mathrm{n}$. gen. can also be discriminated from almost all the other genera on the relative armature of the genital atrium and/or that of the cirrus/penis when present. The following genera have both an armed genital atrium and an armed cirrus: Caballeraxine; Diplostamenides; Lutianicola; Neobivagina; Neobivaginopsis; Pseudobivagina; Pseudoneobivagina; Sciaenacotyle; and Sebasticotyle. Atriostella possesses an armed genital atrium but an unarmed cirrus, whilst species belonging to the genera Diplasiocotyle, Kahawaia, Jaliscia, Microcotyle, Paranaella, Polymicrocotyle and Solostamanides possess an armed genital atrium but no differentiated cirrus. The genera Gamacallum, Magniexcipula and Monomacracanthus have an unarmed genital atrium but an armed penis/cirrus, whilst species belonging to Paramicrocotyloides, Pauciconfibula and

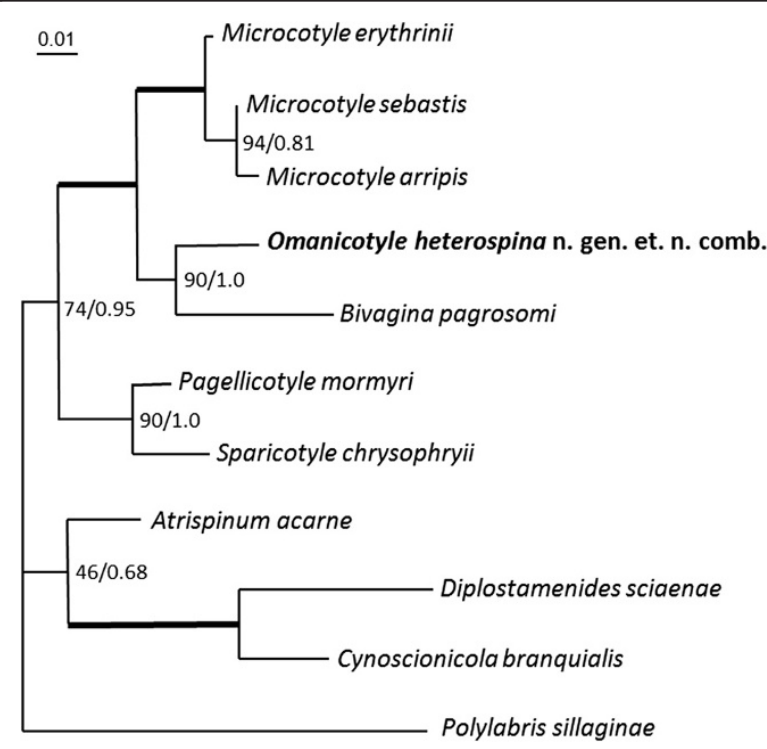

Figure 6 Maximum likelihood phylogenetic tree for the Microcotylidae, based on 11 taxa and 947 characters of aligned LSU rDNA sequence data. Non-parametric bootstrap values and Bayesian inference posterior probabilities are shown at the nodes. Bold branches lead to a node with a high bootstrap support of $\geq 95$ and a Bayesian posterior probability of $\geq 0.98$. The tree is rooted to the outgroup Polylabris sillaginae (Woolcock, 1936) Dillon, Hargis et Harrises, 1983. Scale bar represents 0.01 base changes per 100 bases.
Pseudoaspinatrium have both an unarmed genital atrium and an unarmed cirrus. Only the genera Bivagina and Omanicotyle $\mathrm{n}$. gen. have an unarmed genital atrium and no differentiated cirrus. The latter two genera, however, can be readily separated on the size and armature of their vaginae, as discussed above.

\section{Molecular results}

Both the SSU and LSU regions of the rDNA were successfully sequenced. A nucleotide BLAST search showed that the SSU rDNA of O. heterospina n. gen. et $\mathrm{n}$. comb. was most similar to Microcotyle sebastis with a $99 \%$ identity, and the LSU rDNA was most similar to $B$. pagrosomi, both polyopisthocotylean monogeneans belong to the family Microcotylidae. The phylogenetic analyses produced similar tree topologies (Figure 5), $O$. heterospina $\mathrm{n}$. gen. et $\mathrm{n}$. comb. consistently grouped with B. pagrosomi as a strongly supported sister group to the Microcotyle clade.

\section{Discussion}

There are 24 genera in the subfamily Microcotylinae [17], which, according to Mamaev [18] includes microcotylids that possess a symmetric or sub-symmetric, well-delineated haptor, adults that lack haptoral anchors, intestinal limbs with lateral branches/appendages without anastomoses, an armed or unarmed genital atrium, and, usually a single, medio-lateral, vagina, rarely laterodorsal, but occasionally two, dorso-laterally or ventrolaterally positioned, vaginae. The subfamily Microcotylinae was revised by Unnithan [20] to include six new genera (Atriostella, Diplostamenides, Manterella Unnithan, 1971, Nudimasculus Unnithan, 1971, Polynemicola Unnithan, 1971 and Solastamenides Unnithan, 1971), alongside the four existing genera Metamicrocotyla Yamaguti, 1953, Microcotyle van Beneden et Hesse, 1863, Microcotyloides Fujii, 1944 and Prosomicrocotyla Yamaguti, 1958. This was subsequently revised by Mamaev [18] who moved Polynemicola and Microcotyloides to the subfamily Polynemicolinae Mamaev, 1986; Metamicrocotyla to the subfamily Metamicrocotylinae Yamaguti, 1963; Prosomicrocotyla to the subfamily Prosomicrocotylinae Yamaguti, 1963. Despite their removal from the Microcotylinae, however, no additional comment on the placement of Manterella and Nudimasculus was made. Mamaev [18] then moved a further 14 genera (Bivagina, Caballeraxine, Diplasiocotyle, Gamacallum, Jaliscia, Kahawaia, Lutianicola, Magniexcipula, Monomacracanthus, Neobivagina, Neobivaginopsis, Paramicrocotyloides, Pauciconfibula, Polymicrocotyle, Pseudoaspinatrium, Pseudobivagina, Pseudoneobivagina and Sebasticotyle) into the Microcotylinae. The genera Paranaella [21] and Sciaenacotyle [22] were subsequently added. 
The new genus Omanicotyle gen. n. bears microcotylid-like clamps each with a supplementary lanceolate process (see [18]; Figures 1d, 3c,d, and 5a-f), lack haptoral anchors in the adult, and have intestinal crura of unequal lengths, with short, anterior lateral branches (Figure 1a). The extent of intestinal branching, however, is unknown as much of its length is obscured by vitellaria. No branching was seen in the haptoral peduncle region. Omanicotyle gen $\mathrm{n}$. is erected principally on the basis of the structure and armament of its vaginae, which are evident as two large muscular organs (av. $110 \mu \mathrm{m}$ wide) occupying almost the entire width of each specimen (Figures 1a,e and 2c,d). Each distinct vagina is armed with a complete ring of 16-18 robust spines, confirmed by their positive reaction to the C2Rbased sclerite stain [5] (Figure 3d). While two vaginae are a feature for several genera across the subfamily, the complexity and the degree of variation observed in the armament of these requires supporting molecular studies to unambiguously place species within a genus. Unfortunately, the Microcotylidae are not well represented in the databases with SSU rDNA sequences, however, more data are available for the D1-D2 regions of the LSU rDNA. In addition, the LSU rDNA is known to allow better phylogenetic resolution among monogenean family groups than the SSU counterpart [10]. From Figure 6, it can be seen that Omanicotyle heterospina n. gen. et $n$. comb. is well supported as a member of the subfamily Microcotylinae and as a sister taxon to the Microcotyle, grouping with $B$. pagrosomi (percentage similarity $95.2 \%$; identities $=876 / 920(95 \%)$; gaps $=10 / 920$ (1\%)). Other parts of the phylogeny, however, are not well resolved; Diplostamenides sciaenae (Microcotylinae), for example, groups with Cynoscionicola "branquialis" (Anchoromicrocotylinae Bravo-Hollis, 1981), which is weakly associated with Atrispinum acarne (Atriasterinae Maillard et Noisy, 1979). Additional gene sequence data for more taxa are, therefore, required to fully resolve the phylogenetic relationships amongst the Microcotylidae. Unfortunately, molecular data are also lacking for the purportedly closely related sister taxa of Bivagina, i.e. Pseudobivagina and Neobivagina. All three genera, however, can be separated on the degree of the genital atrium armature. Dillon \& Hargis [23] separated Bivagina, with an unarmed genital atrium, from Neobivagina, with an armed genital atrium. Later, Mamaev [18] separated out Pseudobivagina, possessing a muscular copulatory organ armed dorsally with a semi-crown of rib-like spines, covered with longer ribs arranged in a dome configuration on the walls of the genital atrium. The genital atria of both Bivagina and Omanicotyle heterospina n. gen. et n. comb. are both unarmed. Although Dillon \& Hargis [23] commented on the sclerotised nature of the cirrus (= penis sclerite in [4]) of another Bivagina species, B. sillaginae (Woolcock, 1936) Yamaguti, 1963 [syn. M. sillaginae Woolcock, 1936], they suggested this was atypical and as such the possible basis for its removal from the genus. This was subsequently moved and in Mamaev's [18] revision of the Microcotylidae, this species as Polylabris sillaginae (Woolcock, 1936) has been placed within the subfamily Prostatomicrocotylinae Yamaguti, 1968. The complete armament of the vaginae, however, remains a key feature separating Bivagina species from Omanicotyle heterospina $\mathrm{n}$. gen. et $\mathrm{n}$. comb. Examination of $M$. [Bivagina] centrodonti and B. pagrosomi type material, photographs of B. tai provided by Professor K. Ogawa, and drawings provided in the literature [23-25] suggest that the proportionately small vaginae are predominantly armed with unequal sized spines in their lateral corners whilst the vaginae of Omanicotyle heterospina n. gen. et $\mathrm{n}$. comb. are large, occupying the entire width of the worm and are armed with a full crown of robust, equal-sized spines. One additional feature that may be unique to Omanicotyle n. gen., which may have taxonomic significance, is the consistent, circular region of folded tegument on the dorsal surface (Figure 4a). Likewise, it is not known whether numerous $\mathrm{C} 2 \mathrm{R}$-positive (i.e. suggesting they are of the same proteins forming the hook material) regions distributed along the margins of the anterior portion of the haptor are unique and a definitive statement on these must wait until a detailed confocal microscopy-based study on representative species from each genus in the Microcotylinae can be conducted. The function of both these latter structures also requires confirmation but must await the collection of further specimens.

Although the number of monogeneans encountered in the current study was low, it is not known what impact these polyopisthocotyleans may pose to stock when $A$. spinifer is reared under intensive aquaculture conditions. Given the recorded pathogenicity of other microcotylids on captive held fish stocks (e.g. Bivagina tai [24,26]; Microcotyle sebastis [27]; Sciaenacotyle panceri (Sonsino, 1891) [28]; Sparicotyle chrysophrii (van Beneden et Hesse, 1863) Mamaev, 1984 [29]; and Zeuxapta seriolae (Meserve, 1938) [29-31]), a full assessment of the potential impact Omanicotyle heterospina n. gen. et n. comb. may have is advised before production is initiated.

\section{Conclusions}

The polyopisthocotylean Omanicotyle heterospina $\mathrm{n}$. gen. et n. comb. collected from the gills of the sparid $A$. spinifer is the first monogenean to be described from the Sea of Oman and is assigned to a new genus within the subfamily Microcotylinae (Microcotylidae), based on consistent morphological and molecular differences discriminating it from other genera in the subfamily. 
Morphologically, Omanicotyle n. gen., which possesses two large, fully-armed vaginae, can be discriminated from the genus Bivagina (e.g. B. pagrosomi) on differences in the armament of the vaginae and a characteristic circular, dorsal region of folded tegument. Sequencing of the LSU rDNA (949 bp) revealed only a 95.2\% percentage similarity with B. pagrosomi (identities $=876 / 920(95 \%)$; gaps $=10 / 920(1 \%)$ ), lending support to the proposal that these specimens are placed as a new taxon within the Microcotylinae. A full assessment of the disease potential of Omanicotyle heterospina $\mathrm{n}$. gen. et $\mathrm{n}$. comb. and how it may impact on the production of A. spinifer in Omani waters is advised before production begins.

\section{Competing interests}

The authors declare that they have no competing interests.

\section{Authors' contributions \\ GHY and SAJ sampled the fish, processed the monogeneans for light and scanning electron microscopy (SEM), took photographs and prepared specimens for evaluation by other methods. MAF conducted the molecular analyses. JEB examined specimens with the laser scanning confocal microscope and produced the graphics of the clamps. GP took morphometric measurements, made line drawings and co-defined, with APS, the differential diagnosis. APS prepared and examined specimens using confocal and SEM, made morphometric measurements and line drawings, identified the monogeneans, drafted the species description and the differential diagnosis. GHY, MAF, GP and APS drafted the manuscript. All authors read and approved the final version of the manuscript.}

\section{Acknowledgements}

We thank Professor lan D. Whittington from the South Australian Museum, Adelaide, Australia for his invaluable comments relating to microcotylid morphology; to Dr Gerardo Pérez Ponce de León and Mr Luis García-Prieto from the Instituto de Biología, Universidad Nacional Autónoma de México, Mexico City for the loan of type specimens of Neobivagina from the Coleccion Nacional de Helmintos, Instituto de Biologia, UNAM, Mexico; Mrs Eileen Harris and Tracey Heath from the Parasites and Vectors Section, The Natural History Museum, London for the loan of type specimens of Bivagina and for their assistance in accessing some of the Russian literature relating to microcotylids; Professor Kazuo Ogawa from the Meguro Parasitological Museum, Tokyo, Japan for providing images of B. tai; and, Dr Pavel Gerasev from the Zoological Institute of Russian Academy of Sciences, St Petersburg, Russia for providing images of a paratype of $B$. heterospina. The authors also gratefully acknowledge the support provided by Mrs Nashwa Al-Mazrooei, Director of Fishery Quality Control Center, Ministry of Agriculture and Fisheries Wealth, Oman throughout this project and for her contribution to Omani fish and fisheries research. This study was supported through projects IG/AGR/FISH/13/02, Sultan Qaboos University, Oman, whilst the DNA component of the study was supported by a University of Malaya HIR grant No: UMC/625/1/HIR/027.

\section{Author details}

'Department of Marine Science \& Fisheries, College of Agricultural \& Marine Sciences, Sultan Qaboos University, P.O. Box 34, Al-Khod 123, Oman. ${ }^{2}$ Ministry of Agriculture and Fisheries, P.O. Box 427, Muscat 100, Oman. ${ }^{3}$ Institute of Ocean and Earth Sciences, University of Malaya, Kuala Lumpur 50603, Malaysia. ${ }^{4}$ Institute of Aquaculture, School of Natural Sciences, University of Stirling, Stirling FK9 4LA, UK.

Received: 2 May 2013 Accepted: 21 May 2013

Published: 7 June 2013

\section{References}

1. FAO: Fishery and Aquaculture Country Profiles. Oman; 2011. [http://www.fao.org/ fishery/countrysector/naso_oman/en], last access 06/2011.
2. Froese R, Pauly D: FishBase. World Wide Web electronic publication; 2013. [http://www.fishbase.org], last access 04/2013.

3. Mamaev YL, Parukhin AM: Description of new species of monogeneans Bivagina heterospina sp. nov. and notes on the composition of the genus Bivagina Yamaguti, 1963. Gidrobiol Zh 1975, 2:88-92 [In Russian with English summary].

4. Williams A: Monogeneans of the families Microcotylidae Taschenberg, 1879 and Heteraxinidae Price, 1962 from Western Australia, including the description of Polylabris sandarsae n. sp. (Microcotylidae). Syst Parasitol 1991, 18:17-43.

5. García-Vásquez A, Shinn AP, Bron JE: Development of a light microscopy stain for the sclerites of Gyrodactylus von Nordmann, 1832 (Monogenea) and related genera. Parasitol Res 2012, 110:1639-1648.

6. Hillis DM, Dixon MT: Ribosomal DNA: molecular evolution and phylogenetic inference. Quart Rev Biol 1991, 66:411-453.

7. Freeman MA, Yokoyama $\mathrm{H}$, Ogawa K: A microsporidian parasite of the genus Spraguea in the nervous tissues of the Japanese anglerfish Lophius litulon. Folia Parasitol 2004, 51:167-176.

8. Freeman MA, Yokoyama $\mathrm{H}$, Ogawa K: Description and phylogeny of Ceratomyxa anko sp. n. and Zschokkella lophii sp. n. from the Japanese anglerfish, Lophius litulon (Jordan). J Fish Dis 2008, 31:921-930.

9. Freeman MA, Ogawa K: Variation in the small subunit ribosomal DNA confirms that Udonella (Monogenea: Udonellidae) is a species-rich group. Int J Parasitol 2010, 40:255-264.

10. Wu XY, Chilton NB, Zhu XQ, Xie MQ, Li AX: Molecular and morphological evidence indicates that Pseudorhabdosynochus lantauensis (Monogenea: Diplectanidae) represents two species. Parasitology 2005, 130:669-677.

11. Thompson JD, Gibson TJ, Plewniak F, Jeanmougin F, Higgins DG: The CLUSTAL- $X$ windows interface: flexible strategies for multiple sequence alignment aided by quality analysis tools. Nucl Acids Res 1997, 24:4876-4882.

12. Hall TA: BioEdit: a user-friendly biological sequence alignment editor and analysis program for Windows 95/98/NT. Nucleic Acids Symp Ser 1999, 41:95-98.

13. Guindon S, Dufayard JF, Lefort V, Anisimova M, Hordijk W, Gascuel O: New algorithms and methods to estimate Maximum-Likelihood phylogenies: Assessing the performance of PhyML 3.0. Syst Biol 2010, 59(3):307-321.

14. Ronquist F, Huelsenbeck JP: MrBayes 3: Bayesian phylogenetic inference under mixed models. Bioinformatics 2003, 19:1572-1574.

15. Nylander JAA, Ronquist F, Huelsenbeck JP, Nieves-Aldrey JL: Bayesian phylogenetic analysis of combined data. Syst Biol 2004, 53:47-67.

16. International Commission on Zoological Nomenclature: Amendment of articles 8, 9, 10, 21 and 78 of the International Code of Zoological Nomenclature to expand and refine methods of publication. Zootaxa 2012, 3450:1-7.

17. Shinn AP, Paladini G, Rubio-Godoy M, Domingues MV, Whittington ID, Bron JE: MonoDb. A web-host for Monogenea. World Wide Web electronic publication. 2013. [http://www.monodb.org], last access (04/2013).

18. Mamaev YL: The taxonomical composition of the family Microcotylidae Taschenberg, 1879 (Monogenea). Folia Parasitol 1986, 33:199-206.

19. Tripathi YR: Studies on the parasites of Indian fishes. IV. Trematoda Monogenea, Microcotylidae. Rec Ind Mus Calcutta 1954, 52:231-248.

20. Unnithan RV: On the functional morphology of a new fauna of Monogenoidea on fishes from Trivandrum and environs. Part IV. Microcotylidae sensu stricto and its repartition into subsidiary taxa. Am Midl Nat 1971, 85:366-398.

21. Kohn A, Baptista-Farias M-FD, Cohen SC: Paranaella luquei gen. et sp. $\mathrm{n}$. (Monogenea: Microcotylidae), a new parasite of Brazilian catfishes. Folia Parasitol 2000, 47:279-283.

22. Mamaev Yu L: On species composition and morphological features of the Microcotyle genus (Microcotylidae, Monogenoidea). In Investigations in Parasitology. Collection of papers. Edited by Lebedev BI. Vladivostok: DBNTs AN SSST; 1989:32-38. In Russian.

23. Dillon WA, Hargis WJ: Monogenean trematodes from the southern Pacific Ocean. 2. Polyopisthocotyleids from New Zealand fishes: the families Discocotylidae, Microcotylidae, Axinidae, and Gastrocotylidae. Biol Antarctic Seas Il, Antarctic Res Ser 1965, 5:251-280.

24. Ogawa K: Development of Bivagina tai (Monogenea: Microcotylidae). Nippon Suisan Gakk 1988, 54(1):61-64.

25. Sharples DA, Evans CW: Taxonomy of the metazoan parasites of the snapper Pagrus auratus in New Zealand. New Zeal J Zool 1995, 22(2):143-161 
26. Ogawa K: Occurrence of Bivagina tai (Monogenea: Microcotylidae) on the gills of cultured Red Sea bream Pagrus major. Nippon Suisan Gakk 1988, 54(1):65-70

27. Kim KH, Cho JB: Treatment of Microcotyle sebastis (Monogenea: Polyopisthocotylea) infestation with praziquantel in an experimental cage simulating commercial rockfish Sebastes schlegeli culture conditions. Dis Aquat Org 2000, 40:229-231.

28. Merella P, Cherchi S, Garippa G, Fioravanti ML, Gustinelli A, Salati F: Outbreak of Sciaenacotyle panceri (Monogenea) on cage-reared meagre Argyrosomus regius (Osteichthyes) from the western Mediterranean Sea. Dis Aquat Org 2009, 86:169-173.

29. Paladini G, Hansen H, Fioravanti ML, Shinn AP: Gyrodactylus longipes n. sp. (Monogenea: Gyrodactylidae) from farmed gilthead seabream (Sparus aurata L.) from the Mediterranean. Parasitol Int 2011, 60:410-418.

30. Mansell B, Powell MD, Ernst I, Nowak BF: Effects of the gill monogenean Zeuxapta seriolae (Meserve, 1938) and treatment with hydrogen peroxide on pathophysiology of kingfish, Seriola lalandi Valenciennes, 1833. J Fish Dis 2005, 28:253-262.

31. Hutson KS, Ernst I, Whittington ID: Risk assessment for metazoan parasites of yellowtail kingfish Seriola lalandi (Perciformes: Carangidae) in South Australian sea-cage aquaculture. Aquaculture 2007, 271:85-99.

doi:10.1186/1756-3305-6-170

Cite this article as: Yoon et al:: Omanicotyle heterospina $\mathrm{n}$. gen. et $\mathrm{n}$. comb. (Monogenea: Microcotylidae) from the gills of Argyrops spinifer (Forsskål) (Teleostei: Sparidae) from the Sea of Oman. Parasites \& Vectors 2013 6:170

\section{Submit your next manuscript to BioMed Central and take full advantage of:}

- Convenient online submission

- Thorough peer review

- No space constraints or color figure charges

- Immediate publication on acceptance

- Inclusion in PubMed, CAS, Scopus and Google Scholar

- Research which is freely available for redistribution 